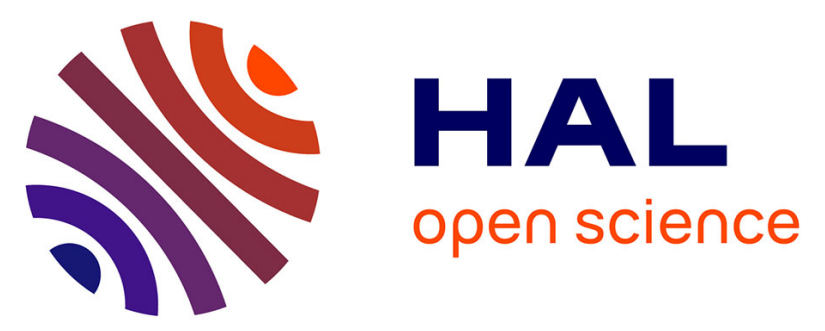

\title{
Proof of concept: Effect of GLP-1 agonist on food hedonic responses and taste sensitivity in poor controlled type 2 diabetic patients
}

\author{
Marie-Claude Brindisi, Laurent Brondel, Sophie Meillon, Sophie Barthet, \\ Sylvie Grall, Claire Fenech, Fabienne Liénard, Pascal Schlich, Karine Astruc, \\ Thomas Mouillot, et al.
}

\section{To cite this version:}

Marie-Claude Brindisi, Laurent Brondel, Sophie Meillon, Sophie Barthet, Sylvie Grall, et al.. Proof of concept: Effect of GLP-1 agonist on food hedonic responses and taste sensitivity in poor controlled type 2 diabetic patients. Diabetes \& Metabolic Syndrome: Clinical Research \& Reviews, 2019, 13 (4), pp.2489-2494. 10.1016/j.dsx.2019.06.021 . hal-02330909

\section{HAL Id: hal-02330909 \\ https://hal.science/hal-02330909}

Submitted on 25 Oct 2021

HAL is a multi-disciplinary open access archive for the deposit and dissemination of scientific research documents, whether they are published or not. The documents may come from teaching and research institutions in France or abroad, or from public or private research centers.
L'archive ouverte pluridisciplinaire HAL, est destinée au dépôt et à la diffusion de documents scientifiques de niveau recherche, publiés ou non, émanant des établissements d'enseignement et de recherche français ou étrangers, des laboratoires publics ou privés.

\section{(ㅇ)(1) $\$$}

Distributed under a Creative Commons Attribution - NonCommerciall 4.0 International 


\section{Proof of concept: Effect of GLP-1 agonist on food hedonic responses and taste sensitivity in poor controlled type 2 diabetic patients.}

Marie-Claude Brindisi MD, $\mathrm{PhD}^{1,2,3}$, Laurent Brondel MD, $\mathrm{PhD}^{1,2}$, Sophie Meillon ${ }^{1,2}$, Sophie Barthet ${ }^{1,2}$, Sylvie Grall ${ }^{1,2}$, Claire Fenech ${ }^{1,2}$, Fabienne Liénard ${ }^{1,2}$, Pascal Schlich ${ }^{1,2}$, Karine Astruc MD ${ }^{4}$, Thomas Mouillot ${ }^{1,5}$, Agnès Jacquin-Piques ${ }^{1,6}$, Corinne Leloup $\mathrm{PhD}^{1,2}$, Bruno Vergès $\mathrm{MD}, \mathrm{PhD}^{3}$, Luc Pénicaud $\mathrm{PhD}^{1,2,7}$

${ }^{1}$ CNRS UMR 6265 Centre des Sciences du Goût et de l'Alimentation F-21000, Dijon, France ${ }^{2}$ INRA UMR 1324 Centre des Sciences du Goût et de l'Alimentation F-21000, Dijon, France

${ }^{3}$ Diabetes and Endocrinology Unit, Dijon University Hospital, F-21000, France

${ }^{4}$ Epidemiology and Hospital Hygene Unit

${ }^{5}$ Gastroenterology Department, Dijon University Hospital, F-21000, France

${ }^{6}$ Neurology Department, Dijon University Hospital, F-21000, France

${ }^{7}$ Stromalab ERL 5311 CNRS, F-31432 Toulouse, France

Corresponding author:

Marie Claude Brindisi: Service de Diabétologie et Endocrinologie. 14 rue Gaffarel. BP77908. 21079 Dijon Cedex, France; Tel : +33(0)3 80293453 ; Fax : +33 (0)3 802935 19; marieclaude.brindisi@chu-dijon.fr

Requests for reprints can be sent to Marie-Claude Brindisi: Service de Diabétologie et Endocrinologie. 14 rue Gaffarel. BP77908. 21079 Dijon Cedex; France 
Word-character count: abstract :180 ; main body of the text : 3152; number of references: 36 ; Numbers of figures: 4; Numbers of table: 1

Clinical Trial : NCT02674893.

Abstract

Aims: GLP-1 analogues decrease food intake and have great promise for the fight against obesity. Little is known about their effects on food hedonic sensations and taste perception in poor controlled patients with type 2 diabetes (T2D).

Materials and Methods: Eighteen T2D patients with BMI $\geq 25 \mathrm{~kg} / \mathrm{m}^{2}$ and poor controlled glycemia were studied before and after 3 months of treatment with Liraglutide. Detection thresholds for salty, sweet and bitter tastes, optimal preferences, olfactory liking, wanting and recalled liking for several food items were assessed. Subjects also answered questionnaires to measure their attitudes to food.

Results: T2D patients had a significant decrease in bodyweight and HbA1c after treatment with Liraglutide. Liraglutide improved gustative detection threshold of sweet flavors, and decreased wanting for sweet foods and recalled liking for fatty foods. It also led to a decrease in feelings of hunger.

Conclusions: Liraglutide increases sensitivity to sweet tastes and decreases pleasure responses for fatty foods in poor controlled T2D patients, and is of particular interest in the understanding of the mechanisms of weight loss.

Keywords: GLP1-analogue, diabetes, food behavior, taste perception. 


\section{Introduction}

Glucagon like peptide-1 (GLP-1) analogues are currently used in the treatment of type 2 diabetes (T2D). In addition to their beneficial glucose lowering effects ${ }^{1}$ (stimulates mealrelated insulin secretions, inhibits glucagon release and delays gastric emptying), GLP-1 analogues have been shown to increase satiety ${ }^{2}$. These compounds have also been shown to reduce food intake and body weight in rodents and humans ${ }^{2-4}$.

GLP-1 receptors (GLP-1Rs) are expressed in the periphery and in several brain areas involved in appetite regulation ${ }^{5,6}$, and the stimulation of both central nervous and peripheral GLP-1Rs result in a decrease in food intake. The peripheral anorectic effects of GLP-1 have been shown to involve humoral and vagal afferent signalling from the gut to the brain ${ }^{7}$. The combined effects of GLP-1, that is to say satiation and weight loss, have great potential for the treatment of overweight or obese individuals with T2D.

Little is known about the effect of GLP-1 analogues on eating behaviour. Eating habits are driven by homeostatic, pleasure and sensory perception systems which are closely related. In rats, 12 weeks of GLP-1 analogue therapy shifted food preferences towards an increase in the consumption of a chow diet and a decrease in candy intake ${ }^{4}$. Furthermore, Shin et al ${ }^{8}$ have shown that GLP-1 is produced in mouse taste cells, and GLP-1 receptors are expressed on the adjacent intragemmal afferent nerve fibres. In addition, behavioural tests showed that GLP-1 receptor knockout mice had a strong decrease in taste responses to sweeteners, suggesting that GLP-1 maintains or enhances sensitivity to sweet tastes ${ }^{8}$. These results suggest a novel paracrine mechanism for the regulation of taste function with GLP-1. In obese type 2 diabetic individuals, a study ${ }^{9}$ used functional MRI to demonstrate that GLP-1 induces increased central nervous system response to the ingestion of palatable foods. A recent study with Semaglutide ${ }^{10}$ has shown in non-diabetic patients less appetite and food cravings, better control of eating and lower relative preference for fatty, energy-dense foods. 
The objective of the present study was to evaluate the impact of liraglutide on taste sensitivity as well as on liking and wanting components of the food reward system in individuals with poor controlled type 2 diabetes yet treated with several antidiabetic drugs and for whom liraglutide treatment seemed well appropriate.

Subjects and materials and methods

Subjects

Eighteen T2D patients ( 6 men, 12 women) were recruited by the department of Endocrinology and Diabetology of the Dijon University Hospital. Liraglutide (NovoNordisk, Puteaux, France) therapy was indicated and prescribed in these patients because they had a body mass index $(\mathrm{BMI}) \geq 25 \mathrm{~kg} / \mathrm{m}^{2}$ and difficulty regulating their blood glycaemia despite previous anti-diabetic treatment.

The patients were between 18 and 80 years old. Exclusion criteria were: impaired kidney function (creatinine clearance $<50 \mathrm{ml} / \mathrm{min}$ ), pregnancy, congestive heart failure, acute and chronic infection, active cancer, cirrhosis, ongoing antibiotic treatment, smoking (more than 5 cig/day), alcohol consumption (more than $20 \mathrm{~g} /$ day), aversion to the foods eaten or smelled during the study, or impaired comprehension for cognitive tasks. Each patient signed a written consent form.

The T2D patients included in the study were first hospitalized in the department of Endocrinology and Diabetology for medical analyses, observations, experimental tests and treatment during 2.5 days. Once the initial tests were carried out, Liraglutide treatment was started. The initial dose was $0.6 \mathrm{mg} /$ day subcutaneously during five days, which was then uptitrated to a daily dose of $1.2 \mathrm{mg}$. After three months of daily treatment, the patients returned to the hospital for a diabetes checkup and to undergo the same experimental tests during half a day, in external consultation. 
Materials and Methods

The experimental tests were carried out in the morning. Blood samples were collected between 8:30 and 9:00 a.m. in patients who had fasted overnight. HbA1c levels were measured immediately after blood sampling by High Performance Liquid Chromatography (Variant, Tosoh Bioscience, Tokyo, Japan). Plasma ghrelin and leptin levels were measured (immediately separated after drawing and stored at $-80{ }^{\circ} \mathrm{C}$ ), using ELISA kits (Millipore, Billerica, USA for ghrelin; R\&D systems, Abingdon, UK for leptin).

Taste detection thresholds were measured for salty, sweet and bitter tastes using the threealternative forced-choice procedure (3-AFC) ${ }^{10}$. The 3 -AFC consists in presenting three opaque plastic cups to the participants. Two of them contain $10 \mathrm{ml}$ of water (Evian) and the other one contains $10 \mathrm{ml}$ of the stimulus (sapid compounds diluted in Evian water). The participant had to taste the three samples and identify which one was different from the other two. The 3-AFCs were presented in ascending order of concentration until the participant correctly identified the stimulus. In this case, the same concentration was given to the participant twice more. If he correctly identified the stimuli, the test was stopped and the detection threshold was designated as the concentration at which the participant made three consecutive correct identifications. If the participant failed to identify the stimulus, the following concentration was presented, and so on ${ }^{11}$. The aqueous solutions containing the stimuli were as follows: 13 saccharose solutions (Cooper, Melun, France), for sweet detection thresholds and 13 sodium chloride solutions (Cooper, Melun, France) for salt detection thresholds with concentrations ranging from 0.001 to $1.0 \mathrm{M}$ (dilutions increasing by increments of $0.25 \log$ units); 13 quinine chlorhydrate solutions (Cooper, Melun, France) with a concentration ranging from 0.0001 to $0.1 \mathrm{mM}$ (dilutions increasing by increments of 0.25 $\log$ units) for bitter taste detection thresholds. 
Optimal taste preferences ${ }^{12}$ were evaluated for cakes, cottage cheese and stewed fruit which were produced in five versions with different fat contents (cakes and cottage cheese) or sugar contents (other cakes and stewed fruit). For each variant of the food item, patients tasted the food and evaluated their experience using a $10-\mathrm{cm}$ visual analog scale with the statements "not pleasant at all" (0) or "very pleasant" $(+10)$ at each extremity.

Olfactory liking and wanting were then evaluated ${ }^{13}$. Olfactory liking was evaluated for food items rich in fat or carbohydrates. Each food was presented separately in a transparent $40 \mathrm{ml}$ cup. The subjects had to sniff the food orthonasally and answer the following question: "When you smell this food, how pleasant would it be to eat a mouthful of this food now?" Olfactory liking was evaluated using $10-\mathrm{cm}$ visual analog scales anchored at each end by the statements "not pleasant at all" (0) and "very pleasant" (+10). To measure wanting, the subjects were shown pictures of foods, some of which were fatty or carbohydrate-rich. The subjects had to look at each picture and to answer the question "How much do you want to eat some of this food now?". Wanting was evaluated using 10-cm visual analog scales with the statements "I do not want any at all" (0) or "I very much want to eat some" (+10) at each extremity.

Then, patients were asked to complete two questionnaires. The objective of the first questionnaire, called PrefQuest, was to measure a subject's recalled liking for fatty-salty, fatty-sweet and sweet (non-fatty) tastes ${ }^{14}$. Contrary to olfactory or flavor liking and optimal preferences, which evaluate pleasure that is experienced concomitantly, PrefQuest collects recalled preferences which are therefore influenced by a different set of external factors. This questionnaire includes different types of items: liking for sweet, fatty-sweet and fatty-salty foods, preferences in the level of seasoning (with sweeteners or fat) and overall questions about sweet- and fat-related behavior. 
Then the Three-Factor Eating Questionnaire (TFEQ) was administered to evaluate attitude to food, dietary restraint, disinhibition (tendency to lose self-control when eating) and hunger ${ }^{15}$.

\section{Statistical Analysis}

To evaluate changes before and after the initiation of liraglutide therapy in T2D patients, the non-parametric Wilcoxon test was used for anthropometric data, treatment modifications, and biological parameters. Correlations between quantitative parameters were calculated by the non-parametric Pearson test. Analyses were conducted using R software 2.14.0, with the level of statistical significance set at $\alpha=0.05$. The statistical analyses for tests evaluating food behaviour and preferences were done with SAS 9.4 software. Differences were considered significant when $\mathrm{p} \leq 0.05$. For each food product from PrefQuest tests, a comparison of the expected normal distribution of the pleasure ratings and the observed distribution for all participants was assessed with a kappa coefficient. The expected distribution was as follows: $10 \%, 20 \%, 40 \%, 20 \%$, and $10 \%$. For the remaining evaluations (wanting, liking, optimal preferences, and taste detection thresholds) a paired T-test was done.

Results

At inclusion, the age of our subjects was $56.5 \pm 8.8$ (mean \pm SD) years and their BMI was $39.2 \pm 6.4 \mathrm{~kg} / \mathrm{m}^{2}$. Mean duration of diabetes was $10.6 \pm 9.1$ years. Mean HbA1c was $8.6 \% \pm$ 1.7. All of the patients taking antidiabetic drugs: $6 / 18(33.3 \%)$ were using insulin, $8 / 18$ (44.4\%) sulphonylurea, 2/18 (11.1\%) glinides, $15 / 18$ (83.3\%) biguanides, and 2/18 (11.1\%) DDP-IV inhibitors (Dipeptidyl peptidase-IV).

After three months of treatment with liraglutide, three of the 6 patients on insulin were able to stop the injections. DPP-IV inhibitors were stopped with the introduction of liraglutide. There were no significant modifications in other oral anti-diabetic treatment (Table 1). 
Three months after the initiation of liraglutide ( $\mathrm{p}=0.0013)$, overall weight loss averaged $4.3 \pm$ $4.2 \mathrm{~kg}$ and a significant improvement in BMI was observed (from $39.2 \pm 6.4 \mathrm{~kg} / \mathrm{m}^{2}$ to $37.6 \pm$ $\left.6.7 \mathrm{~kg} / \mathrm{m}^{2}\right)(\mathrm{p}=0.0011)$.

Blood sugar levels were also better controlled, with a decrease in HbA1c (from 8.6\% to 7.0\%, $\mathrm{p}=0.0003$ ). There was no significant difference in levels of plasma leptin and ghrelin before and after liraglutide treatment (Table 1).

A specific decrease in the detection threshold for sweet and bitter tastes $(p=0.009$ and 0.04 respectively) was observed after three months of liraglutide treatment, which indicates enhanced perception of these tastes. Thresholds for salty, however, remained unchanged (Fig 1).

Optimal preferences for fat decreased at the limit of significance for fat cakes near the end of the treatment $(\mathrm{p}=0.051)$, whereas no significant modifications for fat in cottage cheese or sugar in sweet cakes or stewed fruit were observed (Fig 2a). Results of PrefQuest test show that the recalled liking for fatty-salty and fatty-sweet tastes decreased after liraglutide ( $\mathrm{p}=0.02$ and 0.04 respectively) whereas there was no change for sweet foods (Fig 2b).

Wanting for sweet food decreased significantly with liraglutide treatment ( $\mathrm{p}=0.004)$ (Fig 3). No significant modification was observed for wanting for fatty food. Olfactory liking for fatty and sweet foods decreased with liraglutide treatment, but not significantly even if there is a visible trend $(\mathrm{p}=0.08$ and $\mathrm{p}=0.06$, respectively).

The restraint score, as measured by the TFEQ, was not modified by the liraglutide treatment. In contrast, the hunger and disinhibition scores decreased after three months of treatment ( $\mathrm{p}=0.009$ and 0.003 respectively) (Fig 4). 
We did not observe a significant correlation between weight loss or HbA1c reduction and taste detection thresholds for sweetness ( $\mathrm{p}=0.894$ and $\mathrm{p}=0.270$, respectively) or bitter ( $\mathrm{p}=0.822$ and $\mathrm{p}=0.630$, respectively). It was the same with changes in optimal preferences for fat cakes $(p=0.069$ and $p=0.753)$; changes in recalled liking for fatty-salty $(p=0.537$ and $\mathrm{p}=0.210)$ and fatty-sweet tastes $(\mathrm{p}=0.065$ and $\mathrm{p}=0.210)$; wanting for sweet food $(\mathrm{p}=0.117$ and $\mathrm{p}=0.210)$ and hunger $(\mathrm{p}=0.082$ and $\mathrm{p}=0.210)$. We found a significant correlation between disinhibition and weight loss $(\mathrm{p}=0.047)$ but not with HbA1c improvement $(\mathrm{p}=0.515)$.

\section{Discussion}

The present study provides a detailed analysis of pleasure and taste perceptions in overweight or obese poor controlled type 2 diabetes patients requiring treatment with Liraglutide. Parts of these results corroborate with those observed with non-diabetic patients under Semaglutide in an experimental test ${ }^{10}$.

The strength of our study is that happened in real life, with poor controlled T2D patients, in whom, Liraglutide was expected as a good treatment according to the profile of our patients (overweight and obese patients with part of resistance to insulin). That is why, our ethics committee refused the use of placebo in such unstable diabetic population. That is why too, we had to change therapeutics in our patients according to the introduction of Liraglutide. Indeed we had to stop DPP-IV inhibitors according to the rules following Liraglutide prescription ${ }^{16}$. However, it is known that DPP-IV inhibitors do not influence weight, suggesting no effect on food behavior ${ }^{17}$. And to avoid hypoglycemia with association Liraglutide-insulin, we had to reduce insulin units. So, we cannot exclude impact of therapy modification on these results (less insulin, modification with oral antidiabetic drugs). However, parts of our results are similar to those observed in others studies ${ }^{8,10}$ were subjects or animal models treated with GLP-1 analogue were without other treatment for T2D. 
We demonstrate that Liraglutide leads to a decrease in the detection threshold for sweet tastes, meaning that patients are more sensitive to sweet flavors during treatment. This result corroborates the significant reduction in response to sweeteners described in GLP-1 receptor knockout mice during behavioral tests ${ }^{8}$. Both results suggest that GLP-1 and its analogue enhance sensitivity to sweet tastes. GLP-1 was shown to be produced in mouse taste cells and GLP-1 receptors were shown to be expressed on adjacent intragemmal afferent nerve fibers of mouse taste cells ${ }^{8}$. GLP-1 analogs seem to restore this threshold for sweet taste by resisting DPP-IV inhibition. One study suggested that the detection threshold for sweet tastes is positively correlated with plasma leptin in humans ${ }^{18}$, but leptin levels were not modified by Liraglutide therapy in our study, suggesting that the link with leptin variations does not exist in $\mathrm{T} 2 \mathrm{D}$.

Moreover, we demonstrate that Liraglutide induces a decrease in the detection threshold for bitter tastes, which is a novel observation. In Takai and al ${ }^{19}$, for example, only sweet tastes were modified by GLP-1. A few studies have shown that the activation of bitter taste receptor pathways induces GLP-1 secretion ${ }^{20,21}$, but no study had shown the impact of GLP-1 on the bitter taste threshold.

In our study, optimal preferences for fat cakes, and recalled liking for fatty-salty and fattysweet tastes decreased significantly after treatment with Liraglutide. Here, both tasting and recalled liking, of fatty foods were reduced show a decrease pleasure for fat food. As it is currently accepted that overconsumption of fatty foods increases the risk of cardiovascular diseases ${ }^{22}$, the Liraglutide-induced reduction in recalled liking for fat-rich foods may help in lowering cardiovascular risk in the high-risk population of overweight or obese patients with T2D ${ }^{23}$. This can be added to the significant positive cardiovascular effects of GLP-1 analog described in recent studies ${ }^{24-26}$. Similarly, reduced preference for fatty, energy-dense foods has been observed after Semaglutide treatment, without an increase in energy expenditure ${ }^{10}$. 
The mechanisms responsible for the drop in cravings for fat-rich foods induced by Liraglutide could be related to the intrinsic properties of GLP-1 analogues. Indeed, a reduction in preference for and intake of fat has been observed in rats after bariatric surgery ${ }^{27}$ which is known to increase postprandial GLP-1 levels ${ }^{28,29}$. Bariatric surgery has also been shown to lower the proportion of dietary fat in humans ${ }^{27}$.

We did not observe a variation in ghrelin or leptin under Liraglutide treatment, though several studies have reported a decrease in plasma ghrelin under the same conditions ${ }^{30,31}$. Nonogaki and Suzuki ${ }^{32}$ found that Liraglutide-induced suppression of plasma ghrelin was not related to increased plasma levels of active GLP-1 in fasted mice, but to the suppression of efferent vagus nerve-mediated ghrelin secretions. However, another study did not report changes in ghrelin levels or in other gut hormones like PYY, but reported changes in leptin and GIP levels ${ }^{33}$.

Our data indicate that there is no modification in dietary restriction, but both disinhibition and hunger scores decreased under treatment. These points are relevant to patients' well-being, as GLP-1 analogues increase satiety and decrease food intake without inducing feelings of restriction, and could help patients stick to diets designed for weight loss.

The fact that changes in the thresholds for sweet or bitter tastes, in optimal preferences for fat cakes, in recalled liking for fatty-salty or fatty-sweet tastes, in wanting for sweet foods and in hunger after Liraglutide treatment were not correlated with weight loss and HbA1c improvement indicates that the effect of Liraglutide on food enjoyment and taste perception is likely to be direct. 
We are aware that our study has limitations. Firstly, we lacked a diabetic placebo group (placebo of GLP-1 analog) which would have been tested at 0 and 3 months to confirm the absence of a placebo effect. Studies using placebo included patients with no history past of diabetes and $\mathrm{HbA} 1 \mathrm{c}$ criteria $<6.5 \%{ }^{10}$ or T2D patients with $\mathrm{HbA} 1 \mathrm{c}$ around $6.5 \%{ }^{33}$. In our study, mean $\mathrm{HbA} 1 \mathrm{c}$ was $8.6 \% \pm 1.7$, and our ethics committee refused the use of placebo in an unstable diabetic population. The number of patients is small in our study, but interesting results have been observed in others studies with few patients too and mixed gender ${ }^{10}$. Included patients were hospitalized for medical test, education and treatment adaptation with Liraglutide implementation. The different tests for the study were done just at admission, before medical care or other exams. So, hospital environment was the same that for M3, when they came back. So we do not think that hospital admission could influence the results at M0. We cannot exclude Hawthorne effect and social desirability of our patients; however, our results concerning fatty foods are similar to those recently described by Blundell et al ${ }^{10}$. We included non-smokers or mild smokers patients (less than 5 cigarettes per day) who had not smoked since the day before tests. Heavy smokers were not included. As shown in previous data, only heavy smoking (20+ cig/day) alters gustatory pathways ${ }^{34}$. Concerning smell impairment, it is shown a dose response with increasing number of daily smoked cigarettes ${ }^{34}$, others studies do not find impact of smoking habits (data collected in Thomas -Danguin et al, $2003^{35}$ ). Five or less cigarettes per day can be considered as having few impact on smell capacity. Moreover, patients were their own witnesses, and did not change their smoking habits, during the period of the study. To finish, it is well known that diabetic patients suffer from oral troubles as xerostomia or hyposalivation and these lead to taste disorders and impairment ${ }^{36}$. We cannot exclude that better control of glycemia improve the neuropathy of the taste sensing nerves. Nevertheless our results are concordant with other studies in human or animal models in which there was no diabetes ${ }^{10,8}$ 


\section{Conclusion}

In conclusion, the present proof of concept study conducted on a population of T2D patients with $\mathrm{BMI} \geq 25 \mathrm{~kg} / \mathrm{m}^{2}$ and poor controlled glycemia with several antidiabetic drugs found that liraglutide treatment led to changes in the perceptions of pleasure when eating and the tastes of certain foods. These results corroborate others results conducted in non-diabetic population, or in non real life conditions. Liraglutide treatment led to decreased cravings for fat foods and an enhanced sensitivity to sweet and bitter tastes without affecting the pleasure in eating. These properties are of particular interest in the nutritional care of overweight or obese patients with T2D.

\section{Acknowledgements}

We gratefully acknowledge the help of Emmanuelle Nedelec for measuring plasma ghrelin and leptin levels. We also gratefully acknowledge Suzanne Rankin from the Research Department of the Dijon University Hospital for revising the English. This work was supported by a grant from the Region of Burgundy, France (PARI 2014) awarded to Laurent Brondel and Luc Pénicaud.

\section{References}

1. Drucker DJ, Nauck MA. The incretin system: glucagon-like peptide-1 receptor agonists and dipeptidyl peptidase-4 inhibitors in type 2 diabetes. Lancet. 2006;368:1696-705. 
2. Gutzwiller JP, Drewe J, Göke B, et al. Glucagon-like peptide-1 promotes satiety and reduces food intake in patients with diabetes mellitus type 2. Am J Physiol. 1999; 276:R1541R1544.

3. Astrup A, Rössner S, Van Gaal L, et al. Effects of liraglutide in the treatment of obesity: a randomised, double-blind, placebo-controlled study. Lancet. 2009; 374:1606-1616.

4. Raun K, von Voss P, Gotfredsen CF, Golozoubova V, Rolin B, Knudsen LB. Liraglutide, a Long-Acting Glucagon-Like Peptide-1 Analog, Reduces Body Weight and Food Intake in Obese Candy-Fed Rats, Whereas a Dipeptidyl Peptidase-IV Inhibitor, Vildagliptin, Does Not. Diabetes. 2007; 56:8-15.

5. Göke R, Larsen PJ, Mikkelsen JD, Sheikh SP. Distribution of GLP-1 binding sites in the rat brain: evidence that exendin-4 is a ligand of brain GLP-1 binding sites. Eur J Neurosci. 1995; 7:2294-300.

6. Wei Y, Mojsov S. Distribution of GLP-1 and PACAP receptors in human tissues. Acta Physiol. Scand. 1996; 157:355-357.

7. Rüttimann EB, Arnold M, Hillebrand JJ, Geary N, Langhans W. Intrameal Hepatic Portal and Intraperitoneal Infusions of Glucagon-Like Peptide-1 Reduce Spontaneous Meal Size in the Rat via Different Mechanisms. Endocrinology. 2009; 150:1174-1181.

8. Shin J-K, Martin B, Golden E, et al. Modulation of taste sensitivity by GLP-1 signaling. J Neurochem. 2008; 106:455-463. 
9. Ten Kulve J, Veltman D, van Bloemendaal L, et al. Endogenous GLP1 and GLP1 analogue alter CNS responses to palatable food consumption. Journal of Endocrinology. 2016; 229:112

10. Blundell J, Finlayson G, Axelsen M, et al. Effects of once-weekly semaglutide on appetite, energy intake, control of eating, food preference and body weight in subjects with obesity. Diabetes Obes Metab. 2017; 19:1242-1251

11. Stillman JA. Response selection, sensitivity, and taste-test performance. Percept Psychophys. 1993 Aug;54(2):190-4.

12. Urbano C, Deglaire A, Cartier-Lange E, Herbreteau V, Cordelle S, Schlich P. Development of a sensory tool to assess overall liking for the fatty, salty and sweet sensations. Food Quality and Preference. 2016;48:23-32

13. Berridge KC. Food reward: brain substrates of wanting and liking. Neurosci Biobehav Rev. 1996;20:1-25

14. Deglaire A, Méjean C, Castetbon K, et al. Development of a questionnaire to assay recalled liking for salt, sweet and fat. Food Qual Prefer. 2012; 23:110-124.

15. Stunkard AJ, Messick S. The three-factor eating questionnaire to measure dietary restraint, disinhibition and hunger. J Psychosom Res. 1985; 29:71-83. 
16. Darmon P, Bernard Bauduceau, Lyse Bordier, et al. pour la Societe Francophone du Diabete (SFD). Prise de position de la Société Francophone du Diabète (SFD) sur la prise en charge médicamenteuse de l'hyperglycémie du patient diabétique de type 2. Medecine des maladies Metaboliques - Octobre 2017 - Vol. 11 - $\mathrm{N}^{\circ} 6$

17. Subbarayan S, Kipnes M. Sitagliptin: a review. Expert Opin Pharmacother. 2011 Jul;12(10):1613-22.

18. Nakamura Y, Sanematsu K, Ohta R, et al. Diurnal Variation of Human Sweet Taste Recognition Thresholds Is Correlated With Plasma Leptin Levels. Diabetes.2008; 57:26612665.

19. Takai S, Yasumatsu K, Inoue M,et al. Glucagon-like peptide-1 is specifically involved in sweet taste transmission. FASEB J. 2015;29:2268-80.

20. Kim KS, Egan JM, Jang HJ. Denatonium induces secretion of glucagon-like peptide-1 through activation of bitter taste receptor pathways. Diabetologia. 2014;57:2117-25.

21. Yu Y, Hao G, Zhang Q, et al. Berberine induces GLP-1 secretion through activation of bitter taste receptor pathways. Biochem Pharmacol. 2015;97:173-7.

22. Keys A. Seven countries: a multivariate analysis of death and coronary heart disease. Cambridge 1980; Massachusetts, Harvard University Press 
23. Daousi C, Casson IF, Gill GV, MacFarlane IA, Wilding JPH, Pinkney JH. Prevalence of obesity in type 2 diabetes in secondary care: association with cardiovascular risk factors. Postgrad Med J. 2006; 82:280-284.

24. Marso SP, Daniels GH, Brown-Frandsen K, et al. Liraglutide and Cardiovascular Outcomes in Type 2 Diabetes. N Engl J Med. 2016;375:311-22

25. Marso SP, Bain SC, Consoli A, et al. Semaglutide and Cardiovascular Outcomes in Patients with Type 2 Diabetes. N Engl J Med. 2016;375:1834-1844.

26. Verges B; Charbonnel B. After the LEADER trial and SUSTAIN-6, how do we explain the cardiovascular benefits of some GLP-1 receptor agonists? Diabetes \& Metabolism. 2017;43:2S3-2S12

27. Le Roux CW, Bueter M, Theis N, et al. Gastric bypass reduces fat intake and preference. Am J Physiol Regul Integr Comp Physiol. 2011; 301:R1057-R1066.

28. Le Roux CW, Simon JB, Batterham RL, et al. Gut Hormone Profiles Following Bariatric Surgery Favor an Anorectic State, Facilitate Weight Loss, and Improve Metabolic Parameters. Ann Surg. 2006; 243:108-114. 
29. Morinigo R, Moizé V, Musri M, et al. Glucagon-Like Peptide-1, Peptide YY, Hunger, and Satiety after Gastric Bypass Surgery in Morbidly Obese Subjects. J Clin Endocr Metab. 2006; 91:1735-1740.

30. Hagemann D, Holst JJ, Gethmann A, Banasch M, Schmidt WE, Meier JJ. Glucagon-like peptide 1 (GLP-1) suppresses ghrelin levels in humans via increased insulin secretion. Regul Peptides. 2007; 143:64-68.

31. Senda M, Ogawa S, Nako K, OkamuraM, Sakamoto T and Ito S. The glucagon-like peptide-1 analog liraglutide suppresses ghrelin and controls diabetes in a patient with PraderWilli syndrome. Endocrine Journal. 2012;59:889-894

32. Nonogaki K, Suzuki M. Liraglutide suppresses the plasma levels of active and des-acyl ghrelin independently of active glucagon-like Peptide-1 levels in mice. ISRN Endocrinol. 2013;2013:184753.

33. Farr M, Tsoukas M, Triantafyllou G, et al. Short-term administration of the GLP-1 analog liraglutide decreases circulating leptin and increases GIP levels and these changes are associated with alterations in CNS responses to food cues: A randomized, placebo-controlled, crossover study. Metabolism. 2016; 65:945-95

34. Vennemann M., T. Hummel, K. Berger. 2008. The association between smoking and smell and taste impairment in the general population. J. Neurol. 255: 1121-1126.

35. Thierry Thomas-Danguin, Catherine Rouby, Gilles Sicard et al. Development of the ETOC: A European Test of Olfactory Capabilities*, Rhinology, 41, 142-151, 2003 
36. Borgnakke WS, Anderson PF, Shannon C, Jivanescu A. Is there a relationship between oral health and diabetic neuropathy? Curr Diab Rep.2015 Nov;15(11):93. 


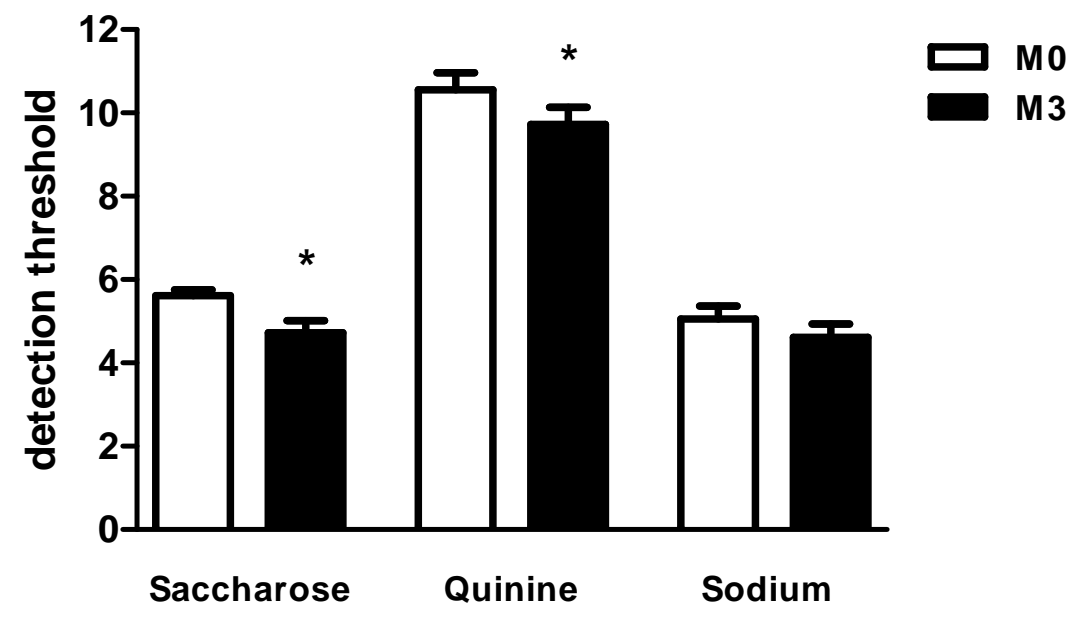

Figure 1: Changes in detection thresholds for sweet (saccharose; mol/l), bitter tastes(quinine; mol/l), and salt (sodium; $\mathrm{mmol} / \mathrm{ll}$ ) after three months of treatment with Liraglutide. ${ }^{*} P \leq 0.05$ when comparing $\mathrm{MO}$ and $\mathrm{M} 3$. 
$2 \mathrm{a}$

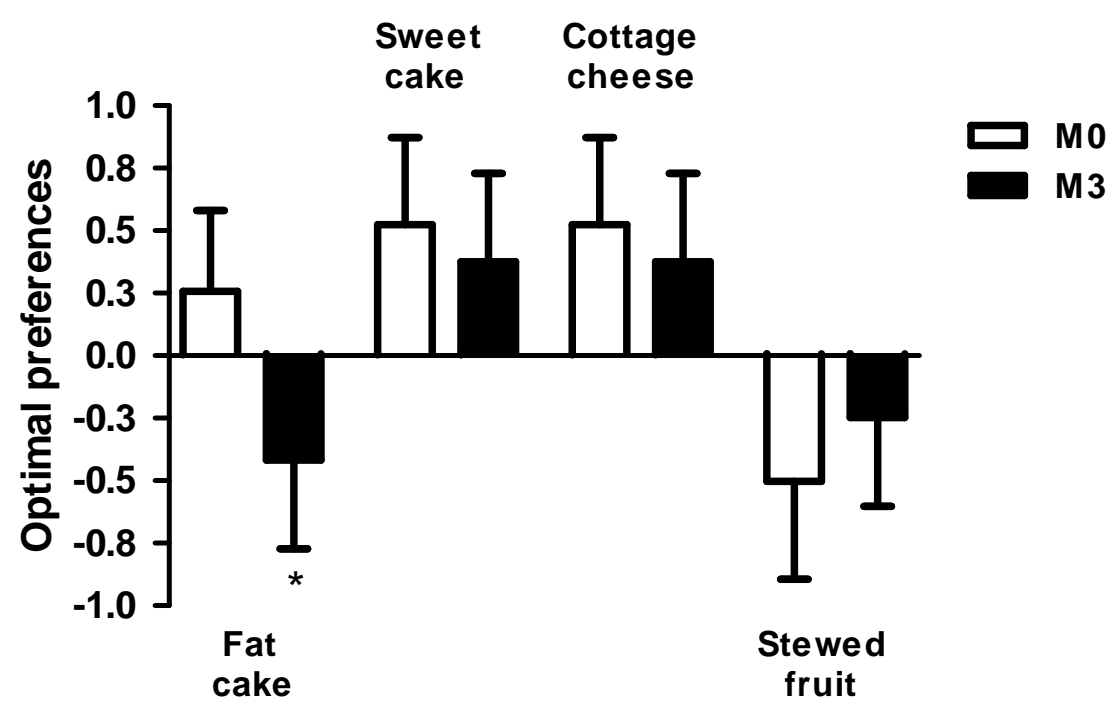

$2 b$

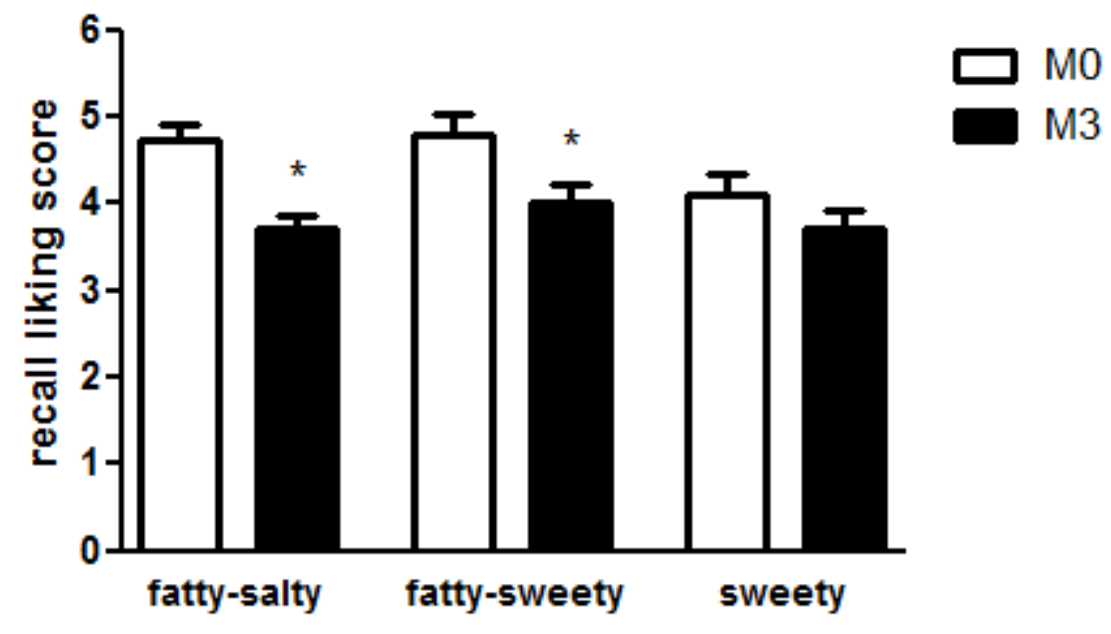

Figure 2: Changes in optimal taste preferences for fatty food (fat cake, cottage cheese), and sweet food (sweet cake and stewed fruit) (2a) and in recalled liking (prefquest test) for fatty-salty, fatty-sweet and sweet foods (2b) after three months of treatment with Liraglutide ${ }^{*} P \leq 0.05$ when comparing $\mathrm{MO}$ and $\mathrm{M} 3$. 


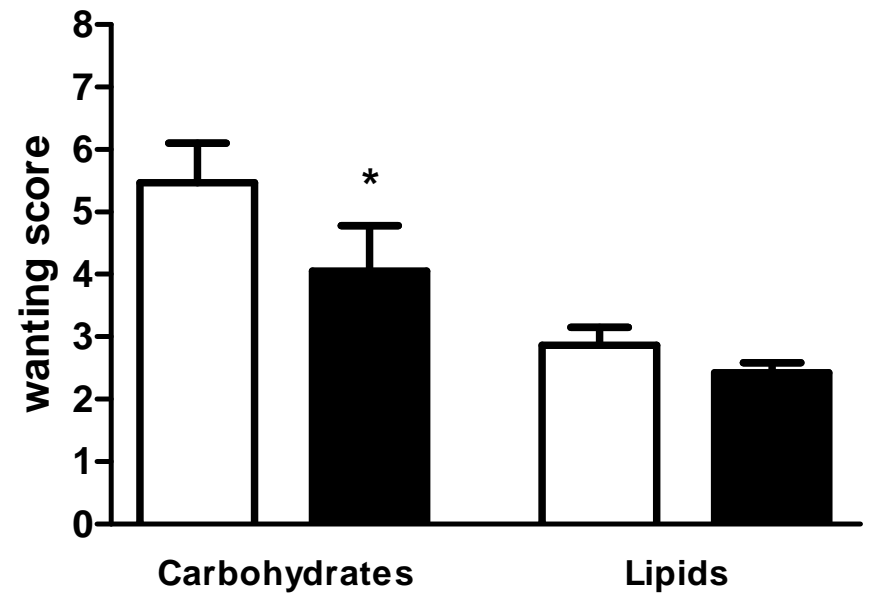

Figure 3. Changes in wanting for carbohydrate and lipid foods after three months of treatment with Liraglutide.

* $p \leq 0.05$ when comparing $\mathrm{MO}$ and $\mathrm{M} 3$. 


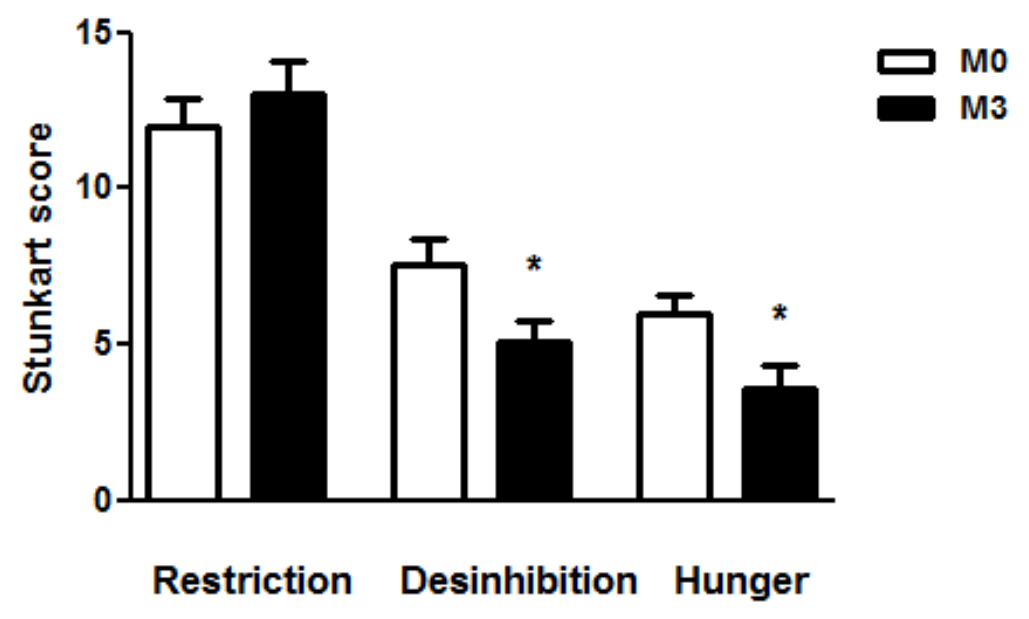

Figure 4: Changes in the three-factor-eating questionnaire score (Stunkard) before (MO) and after a three months of treatment with Liraglutide (M3).

${ }^{*} p \leq 0.05$ when comparing $\mathrm{MO}$ and $\mathrm{M} 3$ 
Table 1 : Changes in antidiabetic treatment, anthropometric parameters (weight and BMI), glycemic control ( $\mathrm{HbA1C}$ ) and leptin and ghrelin hormones before (MO) and after 3 months of treatment (M3) with Liraglutide.

${ }^{*} p$ is significant when $\leq 0.05$.

$\begin{array}{llll} & \mathrm{M} 0 & \mathrm{M} 3 & \mathrm{P} \\ \text { Insulin treatment } & 6 / 18 & 3 / 18 & \mathrm{P}=0.08 \\ \text { Sulfamides treatment } & 8 / 18 & 4 / 18 & \mathrm{P}=0.10 \\ \text { Glinides treatment } & 2 / 18 & 3 / 18 & \mathrm{P}=0.32 \\ \text { Biguanides treatment } & 15 / 18 & 17 / 18 & \mathrm{P}=0.15 \\ \text { DPPIV inhibitors treatment } & 2 / 18 & 0 / 18 & \\ \text { Weight }(\mathrm{kg}) & 106.0 \pm 19.2 & 101.6 \pm 19.7 & \mathrm{P}=0.0013^{*} \\ \text { BMl }\left(\mathrm{kg} / \mathrm{m}^{2}\right) & 39.2 \pm 6.4 & 37.6 \pm 6.7 & \mathrm{P}=0.0011^{*} \\ \text { HBA1c }(\%) & 8.6 \pm 1.7 & 7.0 \pm 0.8 & \mathrm{P}=0.0003^{*} \\ \text { Leptin concentration }(\mathrm{ng} / \mathrm{ml}) & 38.1 \pm 20.6 & 43.2 \pm 28.2 & \mathrm{P}=0.23 \\ \text { Ghrelin concentration }(\mathrm{pg} / \mathrm{ml}) & 5131.8 \pm 2075.3 & 5501.5 \pm 2178.5 & \mathrm{P}=0.42\end{array}$

